\title{
Sowing the seeds of the future: Policies for financing tomorrow's innovations
}

Luca Grilli a $^{\text {, Mariana Mazzucato }}{ }^{\text {, }}$, Michele Meoli c , Giuseppe Scellato ${ }^{\text {d, e }}$

a: Politecnico di Milano, Department of Management, Economics and Industrial Engineering, via R. Lambruschini 4/b, 20156 Milan (MI), Italy, luca.grilli@polimi.it, tel.: +39 0223993955

b: University College London, Institute for Innovation and Public Purpose, Central House, 14 Upper Woburn Place, WC1H 0NN, London, UK, m.mazzucato@ucl.ac.uk, tel.: +44 (0) 2031086173

c: University of Bergamo, Department of Management, Information and Production Engineering, via Pasubio 7/b, 24044 Dalmine (BG), Italy, michele.meoli@unibg.it, tel.: +39 0352052093

d: Politecnico di Torino, Department of Management and Production Engineering, C.so Duca Degli Abruzzi 24, 10129 Torino (TO), Italy, giuseppe.scellato@polito.it, , tel.: +39 0110907270

e: Bureau of Research on Innovation Complexity and Knowledge (BRICK), Collegio Carlo Alberto, Torino Italy.

\begin{abstract}
In this paper, we discuss the state of the art in research and policy making related to the dynamics of financing innovation, highlighting gaps in the literature and setting up the objectives of this Special Issue. We also provide a discussion of methodological issues and future directions for the stream of studies aiming at the evaluation of the effectiveness and impact of policies to finance innovation. Finally, we discuss how the articles in this collection contribute to improve our understanding of the financing of innovation along different perspectives.
\end{abstract}

Keywords: Innovation policy, Financing innovation, R\&D Subsidy, Policy Design, Policy Evaluation. 


\section{Introduction}

Science, technology, and innovation are key pillars for economic growth and competitiveness at the firm, industry, and national levels (Lundvall and Borrás, 2005). While their importance has been highlighted in the literature, and is likely to only increase (Colombo et al., 2011), there are still important issues which remain unresolved. Firstly, the qualitative and analytical models using market failure theory to justify STI policy are potentially limited when the innovation in question are related to transformational shifts and grand challenges (Nelson, 1994; Mazzucato, 2013a), and secondly, solid quantitative and empirical models to support the design of policies promoting technological breakthrough innovation are still scarce (Vilkkumaa et al., 2015).

Countries' and firms' continuous need for increasing investments in knowledge activities underlines the search for competitive advantages (Aghion et al., 2009), and has rendered scientific advancements and the development of new technologies the panacea to the many challenges that current society faces (EC, 2010). Living standards and general socio-economic development are seen to be directly related by advances in information and communication technologies (ICTs), broadband technologies, and next-generation networks. Furthermore, grand challenge around climate change, health and inequality, have caused new types of 'mission oriented' goals around new energy sources which can decrease carbon and greenhouse emissions (Mazzucato and Semieniuk, 2017). Similar mission oriented goals around health mean that genetics and biotechnology are being used to tackle different diseases and famine, as well as increasing the quality and sustainability of our health systems that interact with information technology (Eckardt et al., 2009). Of course, future achievements in terms of growth, production and consumption, crucially depend upon, and are unavoidably shaped by, the decisions, consequent actions and investments made today (Morlacchi and Martin, 2009; Weber and Rohracher, 2012). Such decisions, actions, and investments might be supported by research and innovation policies that must be put in place in economic and institutional contexts that are more intricate than ever before. And yet, while these areas have been well studied, there are three key areas which require further attention. First, while science and technology are increasingly important prerequisites for producing many of today's most valuable long-term innovations (Mazzucato, 2013b), the trio of area of S, T, and I are becoming more intertwined, as seen by the rise in the number of references to scientific literature in patent applications (OECD, 2009). Second, innovation increasingly requires large long-term and the joint endeavours of a large number of stakeholders, including public research institutions, private firms, third sector actors, and dynamic users which may be scattered around the globe (Lange et al., 2013). Consequently, the governance of innovation activities is becoming more challenging. Third, and probably most importantly, the financial crisis has reduced companies’ propensity to invest in long-term, high risk innovation 
projects (Paunov, 2012) and significantly decreased financial capital invested in STI, with a considerable risk of short-termism by all stakeholders in the process of allocation of financial resources (Mazzucato, 2013b; Mazzucato, 2016a). Immediately after the financial crisis governments were required to not only intervene through bailout funds and financial reforms (Wu et al., 2015), but also to lend to those firms (especially SMEs) that were being penalised by the credit crunch. Some studies found that more than a lack of credit there was a differential treatment on the price of credit, with innovative firms being penalised the most (Hughes and Mina, 2012).

These traits, make the nature of the current international STI landscape more complex, and call for improved research approaches in the field of innovation policies for the support to financing STI activities. Policy interventions in the STI domain require new rationales than those typically advocated and confined to market failures in the presence of relevant knowledge spill-overs and capital market imperfections (Mazzucato, 2016b). This modified global scenario calls for new methods and mechanisms for financing scientific and innovation activities all along the global value chains; a re-consideration of the traditional funding tools; and a more granular understanding of the role of the public sector (and of supra-national, national, regional, and local industrial and innovation policy initiatives) for financing STI activities that goes beyond the notion of simply fixing failures.

The issue of financing STI has been addressed in the past two decades by both the finance literature and the literature on innovation studies. However, the former was primarily interested with identifying significant financial barriers and constraints on (firms') investments in R\&D and intangible assets. The latter devoted considerable effort to evaluating those specific policy mechanisms implemented for alleviating (firms') financial constraints and favouring the access of innovative firms to equity markets. There are several contributions in the innovation literature related to financial issues, including studies analysing the effects of different financing sources on firms' R\&D activities or evaluation exercises on specific policy instruments for (firms') innovation performance. Indeed, there are several attempts to look at innovation issues in the finance literature, ranging from the effects of financial constraints on innovation activities to the consequences of public financing in terms of crowding-in/-out effects.

Still, the recent evidence on the dynamics of capital markets (especially after the start of the global financial crisis) suggests how this approach, although relevant, cannot represent the only solution to the risk of underfinancing STI. A more complete, comprehensive, inclusive approach that looks at the whole science and innovation "supply chain” (not just its downstream stages) is needed, together with new policy rationales and tools, especially in science-based areas. During the last decade, much progress has been made in the finance and innovation literature on STI policies and innovation financing, but many questions remain unsolved, and these require for the reasons stated above a more comprehensive approach. In particular, more attention must be placed on institutional features, and 
the dynamic interaction between heterogeneous financial and policy instruments. Addressing this gap is the ambitious goal of this special issue. Our rationale is to provide an opportunity for researchers to create a bridge between these different streams of finance and innovation literatures that, while connected, have not been integrated and thus continue to ignore some of the most pressing questions in the complex global landscape.

A key theme across all the papers in the special issue is the need to better understand how policies can stimulate private investment. We thus use the next section of our introduction, before summarizing the papers in Section 3, to explore in depth recent advances in the assessment of the effectiveness and actual impact of different typologies of public aid, specifically R\&D subsidies and their evaluation. In particular, we highlight a series of key methodological issues on research-design which are key for policy makers to understand the consequences of R\&D subsidies which they implement.

\section{Evaluation of $R \& D$ subsidies: a research mind map}

The importance of R\&D activities to foster economic growth has solid theoretical roots, embracing the work of Schumpeter (1912, 1942), passing through Solow (1956, 1957), arriving to the first (Romer 1986) and subsequent (Romer, 1990; Aghion and Howitt 1992, 1998) waves of endogenous growth theory models. Albeit not unanimous, the relationship between R\&D expenditure and economic performance has also found important empirical validation in the scientific literature (e.g. Griffith et al., 2004). Accordingly, achieving an adequate level of R\&D expenditure has become a key policy statement in virtually all the advanced economies in the world. The pressure on increasing R\&D expenditure is particularly high in the European Union (EU), given the gap suffered in this dimension with respect to international competitors. Allegedly, the increase in R\&D expenditure constitutes the pillar of the most important recent policy actions at the EU level, e.g. the Lisbon strategy in 2000 and the more recent Europe 2020 agenda [see European Commission (EC) (2010)]. In this domain, the main area on which Europe needs to progress is to incentive innovative activities by the private sector. The fact is explicitly acknowledged by the own words of the EC (2010, p. 10, our emphasis): "Europe needs to focus on the impact and composition of research spending and to improve the conditions for private sector $R \& D$ in the EU. Our smaller share of high-tech firms explains half of our gap with the US”. But given the relevance of the objective, a question arises: can public policy play a role in helping these dynamics to unfold?

From one side, the entrepreneurial and innovative activities in modern economies are strongly influenced by several forces ranging from competition policy, the development and functioning of financial markets, to regulatory and law regimes, passing through the patent system and its enforcement. All these dimensions (among others) contribute to shape the interested dynamics. And 
all these dimensions (including also the institutional and cultural context) may be strongly influenced and shaped by the public actor. On the other side, it is also generally accepted that public policy may play a more direct and immediate function in order to improve the conditions for private sector $R \& D$ and increase the share of high-tech firms: in this area, the implementation of R\&D policy subsidies to private firms carves out a major role. Indeed, the ability of 'mission oriented' policies to directly create new technological landscapes which 'crowd in' business by raising the expectations about future growth rates (endogenously creating animal spirits) is one of the most promising areas of research. In this context, indirect policies like subsidies only affect the marginal decisions of how much to invest while limiting the 'additionality' features of making investment happen that would not have happened anyway.

Policy makers tend to justify direct and pro-active types of schemes in the economy in two different ways. First, the likely existence of asymmetric information between the firm and the potential external investors (e.g. banks) on the nature of R\&D activities (Hall and Lerner, 2010). This asymmetry could lead to moral hazard and adverse selection problems and in general to capital market imperfections that may prevent also good $R \& D$ projects to obtain the financing resources they need. Second, the presence of important knowledge spillovers in R\&D activities. To the extent that the returns from innovation investments cannot be fully appropriated by the firm we expect an ex ante decrease in R\&D incentives: investors will be reluctant to invest in that specific activity, leading to the under provision of R\&D expenditure in the economy. Both the "capital market imperfection” and the "spillover" arguments are reputed to hold particularly for high-tech start-ups (see Teece 1986, Storey and Tether 1998, Revest and Sapio 2012).

Consequently, this type of policy scheme, i.e. R\&D public grants to private firms, was in the past and still it is nowadays extremely widespread across nations (and at different governmental levels) to such an extent that is practically impossible to have a record at global level of all these policy interventions.

There is limited scientific knowledge about the efficacy of such interventions. Are they successful in raising the level of private $R \& D$ expenditure (i.e. crowding-in effect) or simply (partly or totally) substitute private resources devoted to innovative activities (i.e. partial or full crowding-out), with the result that global R\&D activities remain unchanged or grows less than proportionally?

A recent survey appeared in the Journal of Economic Surveys carried out by Zuniga-Vicente et al. (2014), counts 77 major scientific studies on the issue conducted from 1960s to nowadays. Out of these 77 , nearly $60 \%$ points to crowding-in, $40 \%$ not. But the number of studies pointing to "additionality" is likely to be inflated for four main reasons. First, Zuniga-Vicente et al. mis-classified some studies (e.g. Gonzales and Pazo, 2008) and/or interpreted the results of some studies as evidence of "crowding-in" effects when they were indeed only tests able at the very best to reject the "full 
crowding-out” hypothesis (e.g. Czarnitzki and Fier, 2002). Second, early studies on the topic do not control for typical endogeneity problems and selection effects in the regression framework, and there is the suspicious that this increased the number of "false positive” effects (David et al., 2000). Third, a publication filter (Griliches 1992) might be at work throughout the years, favoring papers pointing to a positive and statistically significant effect of subsidies with respect to those highlighting negligible effects (Klette et al., 2000). Third, few works controlled for the so called "Goolsbee” effect (Goolsbee, 1998, i.e. the risk that the observed increase in private R\&D expenditure is only a monetary effect, i.e. simply due to the increased salary of scientists and engineers with no "real" effects on the number of new $R \& D$ projects started). And fourth, few studies have looked at the interaction between mission oriented investments, which catalyze innovation across multiple sectors (such as the Apollo project), and the raising of business expectations about the growth of new sectors with consequences on R\&D spending (Mazzucato, 2017).

Considering the survey of Zuniga-Vicente et al. (2014), adjusted for the four points highlighted in the former paragraph, one probably ends up with $50 \%$ (or even less) of the studies pointing to success, $50 \%$ (or even more) of the studies much less optimistic.

The review study by Dimos and Pugh (2015) empirically address some of the limitations of Zuniga-Vicente et al. (2014). The authors make an effort in order to account for publications bias and to derive comparable estimated effects across the different studies by resorting on partial correlation coefficients in the context of multiple meta-regression analyses. Moreover they cluster the analyzed contributions according to the type of additionality (either input or output based) and the quality of information available to the researchers conducting the empirical analyses (e.g. knowledge about the actual amount of the subsidy or just a dummy variable). Having accounted for publication bias, the evidence presented by the authors on the meta-regression analyses (MRA) point to reject crowding out of private investment by public subsidy but reveal no evidence of substantial additionality. In terms of policy implication this would point to the relevance of R\&D subsidies mostly as a form of counter-cyclical measure to sustain R\&D spending in periods of economic downturn, rather than a tool to generate stable and persistent shifts in innovation investment intensity. However, it has to be recalled that MRA aims at isolating average effects and by definition it tends to overlook the role of context-specific moderating factors that likely affects the outcomes of specific policy programs.

As a result, and adopting a global perspective, one is entitled to conclude that after more than fifty years of research, the extant scientific literature on the evaluation of $R \& D$ subsidies is unable to give to policy making clear and neat advices about a) whether implementing a R\&D subsidy or not b) which typology of subsidies (in terms of design, target, and other characteristics) is more likely to breed success. 
Such inconclusiveness might be partly alleviated through advances in methodologies and research design, as detailed in the next section.

\subsection{Methodological advances}

Since the late '90s/ early 2000s, the econometric literature on evaluation of R\&D subsidies has largely progressed due to the availability of fine-grained data (Rogers, 2013), the use to a great extent of longitudinal rather than cross-section data and the more intense application of "endogenous treatment effect methodologies” (e.g. different estimation strategies that include: conditional and unconditional difference-in-difference estimator, control function approaches like selection models, instrumental variable, parametric and non-parametric matching techniques based on propensity scores, regression discontinuity designs, see Cerulli, 2010 for a detailed survey).

Notwithstanding this progress, we believe that there is room for improvement on the methodological side for better understanding the "general equilibrium" implications of a R\&D subsidy.

The typical research framework on which the efficacy of R\&D subsidies is evaluated contemplates the analysis of samples made by "treated" and "untreated" firms, on which treated firms are matched with the most similar "untreated" ones, in order to compute the "average treatment effect on treated firms” (ATT). This type of econometric exercise (among other hypotheses) relies on a fundamental assumption, which is very often neglected and overlooked in the empirical work in the field, i.e. the “stable unit treatment value assumption” (SUTVA), see Wooldridge (2002). SUTVA requires that the 'treatment of unit $i$ affects only the outcome of unit $i$ and does not affect the outcome of the untreated unit $j$ '. It is fairly intuitive that in contexts where SUTVA does not hold, the estimation of ATT (and other related measures, such as the "average treatment effect on untreated firms”, ATU) will be irremediably biased. Therefore an obvious question arises: is SUTVA likely to hold in the context of R\&D subsidies?

Not really. As aforementioned, one of the two rationales for implementing R\&D subsidies is that some R\&D projects will never be undertaken in the economy because they would generate too many spillovers and innovators will not reap enough returns from them. But the existence of R\&D subsidies is intended to make these $R \& D$ projects materialize. Therefore, these subsidized projects once put in place will indeed generate knowledge spillovers. Moreover, note that the better the subsidy is in generating spillovers the less successful it may result in the econometric exercise that compares the performances of treated vs. untreated firms (especially if the untreated firms will increase their own R\&D for absorbing spillovers of treated firms).

At first glance, this may appear as a "catch 22” problem. But we believe that effort is worthwhile in order to alleviate the problem. Grounding on a consolidated and always growing literature on the 
measurement of spillovers that stem from R\&D activities, one important methodological direction to increase our understanding of the true impact of R\&D subsidies is the one of finding new research protocols and novel algorithms that introduce the measurement of KS generated by the subsidy in 'R\&D subsidy evaluation’ exercises.

Proposition 1. To enlarge our perspective on the general equilibrium implications of $R \& D$ subsidies is important to find new research protocols and novel algorithms that duly take into account knowledge spillovers generated by the policy scheme.

All the emphasis on $R \& D$ evaluation literature is on the average effect of the R\&D subsidy. But "average” is only one parameter of a distribution. What about "variance”? From a social-welfare enhancing perspective, a citizen may prefer an $R \& D$ subsidy that on average produces negligible results, but that at the same time it is able to produce (or increase the likelihood of generating) some astonishing outliers. In this respect, despite an initial imprinting (see Mansfield, 1996 for a review of the early literature), the use of qualitative research and case studies analyses has been almost completely dismissed in the recent literature on R\&D subsidy evaluation. Oppositely, the interest for developing and applying research protocols that mix quantitative and qualitative tools in order to analyze social, behavioral, health, and human sciences has gained momentum. In this area, we claim that there is urgent need of developing new "mixed method" research protocol tailored to R\&D evaluation studies.

Proposition 2. To enlarge our perspective on the general equilibrium implications of $R \& D$ subsidies there is the need to develop and apply new "mixed methodologies" that integrate quantitative analysis on the "average treatment effect" of the $R \& D$ subsidy with qualitative analysis aiming at better understanding why subsidies produce outliers ("star performers") and which conditions trigger their arising.

\subsection{Research-design advances}

Typically, researchers evaluate the efficacy of R\&D subsidies by (a) focusing only on "input additionality" and (b) analyzing the effect of a specific R\&D subsidy in isolation with respect to other possible alternative sources of R\&D financing ranging from public (e.g. fiscal incentives) to private (e.g. banks, venture capital, initial public offerings) sources.

Unavoidably, the limited focus on "input additionality” leads to narrowing our understanding of the effects of R\&D subsidies. In addition, ignoring that in many contexts firms may have alternative options to finance innovation rather than simply R\&D grants may lead to an omitted variable problem 
in the estimation of the effect of the R\&D subsidy. More importantly potential complementarities or substitution effects arising from the combination of different instruments might be undisclosed.

Studies performing comparisons between the effects on firm performance of different typologies of R\&D policy measures are extremely rare (few exceptions are represented by Berubè and Mohnen, 2009 in Canada and Busom et al., 2012 in Spain). Klette et al. (2000) counted only 5 major studies on "output additionality" of the R\&D subsidies and the focus on "output additionality" has not dramatically increased since then (see Zuniga-Vicente et al., 2014). Thus, the perspective on R\&D subsidy evaluation should be enlarged by also considering “output additionality” measures, i.e. the effects of the R\&D subsidies on firm output performances like patent activity, productivity and growth.

In the same vein, the effects of R\&D subsidies have been mainly investigated in 'isolation'. In other words, the fact that firms face different institutional contexts and are potentially exposed to more policy schemes (e.g. fiscal incentives to R\&D activities) and private financing sources (e.g. bank debt, venture capital, etc.) than simply R\&D subsidies has been largely ignored in the empirical investigations of the efficacy of R\&D subsidies. Thus, we claim that there is the need to better evaluate the synergistic effects potentially arising across different public policy measures and between them and other private sources of financing.

Proposition 3. To increase the informative content of $R \& D$ policy evaluation studies there is the need (a) to consider different “additionality” options and (b) find potential complementarities or substitution effects with other public and/or private sources of financing.

One of the potentially most beneficial effect of being granted with an R\&D subsidy is the “certification” or "stamp of approval” effect that may stem from it (see Lerner, 1999, 2002 who first put forward this hypothesis and Howell, 2017 for a more recent and skeptical, although not definitive, view as to its arising in relation to the U.S. SBIR). This latter 'indirect' effect may prove to be essential as the 'direct' one by easing the access of the subsidized firm to external tangible and intangible resources that will be out of reach without a reputational gain obtained with the subsidy. But the very nature of this indirect effect theorized by many scholars remains largely unknown: is this automatic? Or conversely it will arise only if the grant is associated with specific characteristics of the subsidy and of the recipient firm? These are important issues, especially nowadays where national budget are severely constrained.

Proposition 4. To increase the informative content of $R \& D$ policy evaluation studies there is the need to dig into the certification effect of $R \& D$ subsidies and find potential triggering and 
moderating factors of its impact at various levels of analysis (i.e. considering different characteristics of the subsidy and of the recipient firm).

\subsection{Developing a research mind map}

We believe that all the four propositions are equally important and the directions they indicate for future research could significantly improve our understanding of the effects of R\&D subsidy schemes in the economy. But we also view them as interconnected, i.e. with the pursuing of one offering insights also to another dimension. Below we illustrate such interlinks.

The first proposition concerns the need of theoretical advances in findings new algorithms and new methods for incorporating selected measures of knowledge spillovers in evaluation exercises of R\&D subsidies. In this regard, one possible research strategy might consist in the classification of untreated firms along different degrees of exposure to knowledge spillovers (KS). The comparison between treated and untreated firms differently exposed to KS, will enable to "isolate" the direct effect of the subsidy (e.g. [effect on treated firm] - [effect on untreated not exposed to KS]) from the indirect one (e.g. [effect on untreated exposed to KS] - [effect on untreated not exposed to KS]). This possibility is viable to the extent that the researcher is capable to control for those external (to the subsidy) factors that can affect the untreated units of analysis and observe different outcome performances than just input additionality. ${ }^{1}$ This brings to the third proposition about the need to investigate complementary or substitution effects across different typologies of public support (e.g. R\&D grants vs. R\&D fiscal incentives) and between $R \& D$ subsidies and other private forms of $R \& D$ financing (e.g. venture capital). In doing so, taking into account KS and possible synergistic or substitution effects between different forms of R\&D financing and different additionality measures, it is equally important to consider the need of adopting new "mixed research methods" (see Proposition 2). Different established protocols do exist in this respect (i.e. the Convergent Parallel Design, the Explanatory Sequential Design, the Exploratory Sequential Design, the Sequential Transformative Strategy, the Concurrent Triangulation Strategy, the Embedded Design among others, see Terrell, 2012) used mostly in the health sciences (see Creswell et al., 2011). In this regard, the key objective is to assess how these methods would perform in the "R\&D subsidy evaluation". Finally, some characteristics of the grants or of the recipient firm are better able than others to trigger the certification effect of the R\&D subsidy. Here specific attention should be dedicated to a) specific characteristics of the selection procedure (e.g. appointment of central committees vs. selection

\footnotetext{
${ }^{1}$ Interesting insights on possible ways to consider KS in R\&D policy evaluation exercises may also arise from the tangent literature on "peer effects” in treatment response models (see Athey and Imbens, 2017 for a recent review).
} 
procedure demanded to local entities) and b) entrepreneurs' human capital (e.g. educational background, work experience in different field, technical and managerial skills).

Although each single proposition formulated in the paper is worth of reflection and could represent an important advancement in the stream of R\&D policy evaluation, we believe that their joint consideration may represent more than the sum of the parts, by enabling a more thoughtful answer to the (not yet resolved) puzzling question: are direct public R\&D subsidies really impactful?

\section{Overview of contributions in the special issue}

All the twelve papers in this special issue contribute to a better understanding of the relationship between innovation policies and the financing of innovation. They do so by addressing five complementary areas: i) innovation policies for funding large-scale research projects addressing grand societal challenges; ii) the design of policies to facilitate finance for innovation; iii) the role of science and higher-education institutions; iv) the role and contribution of financial markets to innovation; v) the development of innovative financing channels for science.

Two papers explore which policies might facilitate financing breakthrough innovations, with a specific reference to sustainability and grand social challenges. Mazzucato and Semieniuk (2017) analyse how successful financing of innovation in renewable energy (RE) requires a better understanding of the relationship between different types of finance, and their willingness to invest in RE. The authors study the 'direction' of innovation that financial actors create (finance is not 'neutral'), focusing on the deployment phase of innovation, and relying on Bloomberg New Energy Finance (BNEF) data to construct a global dataset of renewable energy asset finance flows from 2004 to 2014. Thus, they analyse the asset portfolios of different renewable energy technologies financed by different financial actors according to their size, skew and level of risk. According to their results, financial actors vary considerably in the composition of their investment portfolio, creating a direction towards particular technologies. In particular, public financial actors invest in portfolios with higher risk, and tend to increase their share in total investment dramatically over time.

Along this line, Falcone et al. (2017) examine the use of language and depict the emerging storylines surrounding the green finance (GF) niche. They scrutinize the narratives used by landscape actors to assess the channels through which a pressure towards a greener economy is exerted, as well as its effectiveness. Their findings reveal a high/unbalanced narrative pressure coming from global actors by means of both institutional and informal channels, and from national actors mainly by means of informal channels. If no appropriate policy interventions are undertaken, such inadequacy could jeopardize the development of green innovations. More specifically, their study support decision makers in developing specific strategies to unlock the huge potential of GF in the transition process 
towards a greener economy by: i) supporting a deeper strategic collaboration among informal and institutional actors operating at the national level; ii) acting as catalysts of green-oriented financial initiatives and related dissemination; and iii) readdressing the national-institutional actors towards a more proactive role in fostering finance for green innovation.

A second group of contributions analyses how policy schemes can be designed, and the interaction with the innovation context. As far as design is concerned, D’Andria and Savin (2017) explore effects of two distinct tax policies on innovation in a pure knowledge economy: an 'IP box' incentive and a (hypothetical) tax incentive on compensation earned by agents from profit sharing schemes (PSS). In contrast to the conventional assumption that firms decide on whether to innovate or not, they focus on a bottom-up innovation process, where firms set incentives to fulfil different tasks, but the final decision on whether to make the more innovative task is taken by an employee. They compare the two tax incentives under several distinct specifications demonstrating that the tax incentive on PSS can be a powerful mechanism fostering innovative activity and benefiting at the same time workers, firms and the economy as a whole. Their study shows that the more critical for firms is the issue of attracting and motivating highly skilled workers, the larger is the expected gain from employing the tax incentive on agents' compensation. In addition, they find that the relative efficacy of this tax incentive scheme is moderated by labour mobility and the extent of knowledge spill-overs.

Liotard and Revest (2017) provide an interesting perspective on how policies interact with the innovation context, by focus on the increase of the innovation contests and their associated prizes that have been observed since the 90s, especially in the US through the sponsorship of the American Federal Agencies. The purpose of their article is to shed light on some of the direct and indirect effects of US federal agency contests not only on economic but also social dynamics. . Based on recent case studies, this paper describes the various positive impacts that federal agency contests may have: i) contests may display a strong incentive effect ex-ante and during the contest; ii) they may produce favourable spill-overs after the contests, at innovation and economic levels in specified economic/industry sectors and iii) they may also play a beneficial social role, contributing to citizens' education and awareness. Nevertheless, as a contest remains a sophisticated device, public decision makers must comply with certain requirements if they wish to benefit from this particular policy tool in order to spur innovation.

The third area of this special issue focuses on the link between higher education institutions and innovation, as well as on the interaction with other institutions. Munari et al. (2017) address the direct contribution of higher education institutions to funding. They argue that the limited availability of private funding sources to support technology transfer activities represents a major barrier to the effective commercialization of university technologies. This is why their article analyses the key determinants of the activation of financial instruments by universities—such as seed funds and proof- 
of-concept programs - to address such funding gaps. Using data from a survey of technology transfer office managers in European universities, they detail the antecedents of the presence of such instruments at the university level and their perceived effectiveness. The findings, in turn, have notable policy implications.

Okamuro and Nishimura (2017) look at the interaction of higher education institutions with external actors. Their contribution studies how the governments can support research and development $(\mathrm{R} \& \mathrm{D})$ consortia between universities and industry through public subsidies, in order to promote innovation. In the first decade of this century, two ministries of the Japanese government, Ministry of Economy, Trade and Industry (METI) and Ministry of Education, Culture, Sport, Science and Technology (MEXT), began independently implementing cluster policies for R\&D consortia with the same purpose, though with contrasting policy designs. While private firms can play a leading role and obtain a considerable share of the METI subsidy, they are the subcontractors to the university partners, and thus, cannot gain a direct share of the MEXT subsidy. Focusing on the Japanese policies, they empirically investigate how participating firms' commitment toward R\&D projects differ between these cluster programs and examine whether the firms' commitment enhances project performance (i.e., commercialization of R\&D outcomes) using original and comparable survey data. The estimation results suggest that the participants of the METI program demonstrate a significantly higher commitment when compared to the participants of the MEXT program, and that project performance significantly depends on firm commitment. A major policy implication is that when commercialization is important for the government, it should consider firm commitment in policy design.

Archibugi and Filippetti (2017) question what are the differences when research is conducted by the private business rather than in universities or government research centres. While most of the attention of science and innovation policy in the last decades has explored the relevance of the interconnections between public and business players in enhancing knowledge-based societies, a major trend has been ignored: both the quota of public $R \& D$ and its share over the total $R \& D$ investment has shrunk in the majority of OECD countries. As a result, a larger fraction of knowledge is today generated in the business sector. They argue that this is a major problem since public research and private research differ along a number of characteristics, e.g. public access, potential for future technological innovations, criteria of resource allocation. This trend can have adverse implications for long-term innovation and economic welfare in our societies.

A fourth section of this special issues features three papers contributing on the macro-perspectives on financial markets, innovation, high-tech entrepreneurship and economic growth. Polzin et al. (2017) analyse how entrepreneurs and investors face challenges in the 'thin market' for early stage entrepreneurial finance. Improving this situation has been a priority of policy makers for at least a 
decade, however, the challenges in this matching process are still poorly understood. Theory suggests that matching problems may originate in different perceptions in areas such as evaluation criteria, risk and risk management by investors and entrepreneurs. To find a good match it seems essential to understand what is important to the other's counterpart. Based on a mixed methods approach using data collected in semi-structured interviews and a survey with both entrepreneurs and investors mostly active in green tech innovation, this study systematically analyses where frictions in the matching process may occur. The authors find that a mismatch exists in the perception of risk, the importance attached to risk, the search channels used to find a potential partner and the evaluation criteria applied in evaluating a proposition (i.e., exit, innovativeness, capabilities of teams). The paper suggests that increasing market transparency and creating a mutual understanding of the investment process will prevent potentially damaging perceptions' misalignment from arising in the first place.

García-Quevedo et al. (2017) are motivated by the fact that, although many innovation projects are abandoned before completion, the empirical evidence has focused on the determinants of innovation, while failed projects have received little attention. Their paper analyses the role of financial obstacles on the likelihood of abandoning an innovation project by potentially innovative Spanish firms for the period 2005-2013. Their analysis differentiates between the impacts of internal and external barriers on the probability of abandoning a project, and examine whether barriers differ depending on the stage of the innovation process. Controlling for potential endogeneity, they use a bivariate probit model to take into account the simultaneity of financial constraints and the decision to abandon an innovation project. Their results show that it is during the conception stage that financial constraints have their greatest effect on the probability of abandoning an innovation project. In addition, the financial sources are not neutral across the innovation project lifecycle. During the design phase, Spanish firms are more sensitive to internal financial sources while, during the execution stage, they are more sensitive to external sources.

Signori and Vismara (2017) argue that the recent decline in IPO activity can be explained by the small firms' increasing preference for being acquired rather than growing independently. Their paper sheds light on this explanation by focusing on the nature of the firms facing this decision and their potential merger synergies. First, the above explanation should be particularly true for Young Innovative Companies (YICs), which are often superior to incumbents in originating innovations but face greater difficulties in bringing them to the market. Second, a firm's trade-off between being acquired and remaining independent strongly depends on the extent of the synergies arising from a potential merger, which are however difficult to assess ex-ante. Using a new, text-based measure of business similarity as a proxy for M\&A synergies, they document that YICs facing the potential to develop larger synergies are the main responsible for the decline in IPOs. Compared to 15 years ago, the quarterly number of IPOs conducted by these firms has decreased by 20 units. At the same time, 
while M\&A activity of other firms has declined, the number of acquisitions involving this particular type of firms has remained stable over time.

Finally, two papers in this special issue look at what are the opportunities, challenges and critical factors related to innovative channels for finance. Arena et al. (2017) perform a critical analysis of the financial instruments that can be employed to fund social innovation, with a specific focus on social tech start-ups that develop and deploy technology-driven solutions to address social needs in a financially sustainable manner. The paper analyses how these start-ups can access financing, the barriers to financing that these organisations experience and the financial instruments that are most suitable to address their financial needs. Social tech start-ups have many points of overlap with hightech start-ups in terms of the financing barriers they encounter in different lifecycle stages. Still, the institutional solutions that are commonly exploited by high-tech start-ups for growth are not enough to support the scaling up of social tech start-ups. Therefore, authors introduce the concept of Social Impact Investment (SII) and discuss its potential contribution to the social tech finance landscape. Then, using the case of social tech start-ups as a paradigmatic case of the broader problem of financing mechanisms for social innovation, they formulate a research agenda, including directions for research and theoretical development in the field of SII.

Finally, Cowling et al. (2017) consider that high-technology firms per se are perceived to be more risky than other, more conventional, firms. It follows that financial institutions will take this into account when designing loan contracts, and that this will manifest itself in more costly debt. In this respect, they empirically test whether the provision of a government loan guarantee fundamentally changes the way lenders price debt to high-tech firms. Furthermore, authors also examine whether there are differential loan price effects of a public guarantee depending on the nature of the firms themselves and the nature of the economic and innovation environment that surrounds them. Using a large UK dataset of 29,266 guarantee backed loans they find that there is a high-tech risk premium which is justified by higher default, but, in general, that this premium is altered significantly when a public guarantee is provided for all firms. Further, all these loan price effects differ on precise spatial economic and innovation attributes.

\section{Conclusion}

Schumpeter placed innovation at the centre of his understanding of capitalism. As innovation must be financed (internally or externally), finance must also at the centre of any theory of capitalist economies. Indeed, he called the banks the 'ephors' of the exchange economy. We hope this special issue will help to unpick the key relationships, across organisations, institutions and instruments, that help better understand this core feature of capitalist systems, and how to engage finance with not only the rate of innovation but also its direction. 


\section{References}

Adams, J.D., Jaffe, A.B. (1996). Bounding the effects of R\&D: an investigation using matched establishment-firm data. RAND Journal of Economics 27, 700-721.

Aghion, P., Howitt, P. (1992). A Model of Growth through Creative Destruction. Econometrica 60, 323-351.

Aghion, P., Howitt, P. (1998). Endogenous Growth Theory. MIT Press, Cambridge, MA.

Aghion, P., David, P.A., Foray, D. (2009). Science, technology and innovation for economic growth: Linking policy research and practice in STIG Systems. Research Policy, 38, 681-693.

Andersson, T., Asplund, O., Henrekson, M. (2002), Betydelsen av Innovationssystem, Utmaningar för Samhället och för Politiken, Stockholm: VINNOVA.

Archibugi, D., Filippetti, A. (2017). The Retreat of Public Research and its Adverse Consequences on Innovation. Technological Forecasting \& Social Change.

Arena, M., Bengo, I., Calderini, M., Chiodo, V. (2017). Unlocking finance for social tech startups: is there a new opportunity space? Technological Forecasting \& Social Change.

Athey, S., Imbens, G.W. (2017). The State of Applied Econometrics: Causality and Policy Evaluation. Journal of Economic Perspectives 31, 3-32.

Bertoni, F., Martí, J. (2011). Financing Entrepreneurial Ventures in Europe: The VICO Dataset. SSRN wp 1904297.

Berubè, C., Mohnen, P. (2009). Are firms that receive R\&D subsidies more innovative? Canadian Journal of Economics 42, 206-225.

Busom, I., Corchuelo, B., Ros, E.M. (2012). Tax incentives or subsidies for R\&D? UNU-Merit wp 2012-056.

Cerulli, R. (2010). Modelling and Measuring the Effect of Public Subsidies on Business R\&D: A Critical Review of the Econometric Literature. Economic Record 86, 421-449.

Colombo, M.G., Giannangeli, S., Grilli, L. (2013). Public subsidies and the employment growth of high-tech start-ups: assessing the impact of selective and automatic support schemes. Industrial and Corporate Change 22, 1273-1314.

Colombo, M.G., Grilli, L., Piscitello, L., Rossi-Lamastra, C. (2011). Science and Innovation Policy for the New Knowledge Economy. Edward Elgar: Cheltenham, UK.

Cowling, M., Ughetto, E., Lee, N. (2017). The innovation debt penalty: Cost of debt, loan default, and the effects of a public loan guarantee on high-tech firms. Technological Forecasting \& Social Change.

Creswell, J.W., Klassen, A.C., Plano Clark, V.L., Smith, K.C. (2011). Best practices for mixed methods research in the health sciences. National Institutes of Health. 
Croce, A., Martì, J., Murtinu, S. (2013) The Impact of Venture Capital on the Productivity Growth of European High-Tech Firms: 'Screening' or 'Value Added' Effect? Journal of Business Venturing 28, 489-510.

Czarnitzki, D., Fier, A. (2002). Do Innovation Subsidies Crowd Out Private Investment? Evidence from the German Service Sector. ZEW Discussion Paper 02-04.

David, P.A., Hall, B.H., Toole, A.A. (2000). Is public R\&D a complement or substitute for private R\&D? A review of the econometric evidence. Research Policy 29, 497-529.

Dimos, C., Pugh, G. (2016) The effectiveness of R\&D subsidies: A meta-regression analysis of the evaluation literature, Research Policy.

D’Andria, D., Savin, I. (2017). A Win-Win-Win? Motivating innovation in a knowledge economy with tax incentives. Technological Forecasting \& Social Change.

Eckardt, N., Cominelli, E., Galbiati, M., Tonelli, C. (2009). The future of science: food and water for life, Plant Cell 21(2), 368-372.

European Commission (2010). Europe 2020: A Strategy for Smart, Sustainable and Inclusive Growth.

Falcone, P. M., Morone, P., Sica, E. (2017). Greening of the financial system and fuelling a sustainability transition. A discursive approach to assess landscape pressures on the Italian financial system. Technological Forecasting \& Social Change.

García-Quevedo, J., Segarra-Blasco, A., Teruel, M. (2017). Financial constraints and the failure of innovation projects. Technological Forecasting \& Social Change.

Gonzales, X., Pazo, C. (2008). Do public subsidies stimulate private R\&D spending? Research Policy 37, 371-389.

Goolsbee, A. (1998). Does Government R\&D Policy Mainly Benefit Scientists and Engineers? American Economic Review 88, 298-302.

Griffith, R., Redding, S., Reenen, J.V. (2004). Mapping the two faces of R\&D: productivity growth in a panel of OECD industries. Review of Economics and Statistics 86, 883-895.

Griliches, Z. (1992). The search for R\&D spillovers. Scandinavian Journal of Economics 94, S29S47.

Hall, B.H. and Lerner, J. (2010) The financing of R\&D and innovation. In Hall, B.H. and Rosenberg, N. (eds.), Handbook of the Economics of Innovation, Vol. I, pp. 609-639. New York: Elsevier/North Holland.

Howell, S.T. (2017). Financing innovation: Evidence from R\&D grants. American Economic Review 107, 1136-1164.

Hughes, A., Mina, A. (2012). The UK R\&D Landscape: Enhancing value taskforce. CIHE and UK Innovation Research Centre. 
Klette, T.J., Mǿen, J., Griliches, Z. (2000). Do subsidies to commercial R\&D reduce market failures? Microeconometric evaluation studies. Research Policy 29, 471-495.

Lange, K., Müller-Seitz, G., Sydow, J., Windeler, A. (2013). Financing innovations in uncertain networks-Filling in roadmap gaps in the semiconductor industry. Research Policy, 42, 647-661.

Lerner, J. (1999). The government as venture capitalist: the long-run impact of the SBIR program. Journal of Business 72, 285-318.

Lerner, J. (2002). When bureaucrats meet entrepreneurs: the design of effective 'public venture capital’ programmes. Economic Journal 112, F73-F84.

Liotard, I., Revest, V. (2017). Contests as innovation policy instruments: lessons from the US federal agencies' experience. Technological Forecasting \& Social Change.

Lundvall, B.A., Borrás, S. (2005). Science, technology and innovation policy. The Oxford Handbook of Innovation. 599-631.

Mansfield, E. (1996). Contributions of new technology to the economy. In: Smith, B.L.R., Barfield, C.E. Eds., Technology R\&D and the Economy, Brookings Institution and AEI, Washington, DC, 114-39.

Mazzucato, M. (2013a). The Entrepreneurial State: Debunking Private vs. Public Sector Myths. Anthem Press: London. ISBN 9780857282521.

Mazzucato, M. (2013b). Finance, innovation and growth: Finance for creative destruction vs. destructive creation. Industrial and Corporate Change, 22, 869-901.

Mazzucato, M. (2016b) "From Market Fixing to Market-Creating: A new framework for innovation policy", Special Issue of Industry and Innovation: "Innovation Policy - can it make a difference?”, 23 (2)

Mazzucato, M., Semieniuk, G. (2017). Financing renewable energy: Who is financing what and why it matters. Technology Forecasting \& Social Change.Mazzucato, M. (2016a) "Innovation, the State and Patient Capital”, in Rethinking Capitalism Economics and Policy for Sustainable and Inclusive Growth, Chapter 6. Eds Jacobs, M. and Mazzucato, M, Wiley-Blackwell, London, UK

Morlacchi, P., Martin, B.R. (2009). Emerging challenges for science, technology and innovation policy research: A reflexive overview. Research Policy, 38, 571-594.

Munari, F., Sobrero, M., Toschi, L. (2017). The University as a Venture Capitalist? Gap Funding Instruments for Technology Transfer. Technological Forecasting \& Social Change.

Nelson, R. R. (1994). The co-evolution of technology, industrial structure, and supporting institutions. Industrial and corporate change, 3(1), 47-63.

OECD (2009). OECD Economic Outlook, 2(86), OECD, Paris. 
Okamuro, H., Nishimura, J. (2017). Whose Business is Your Project? A Comparative Study of Different Subsidy Policy Schemes for Collaborative R\&D. Technological Forecasting \& Social Change.

Paunov, C. (2012). The global crisis and firms' investments in innovation. Research Policy, 41, 24-35.

Polzin, F., Sanders, M., Stavlöt, U. (2017). Do investors and entrepreneurs match? - Evidence from the Netherlands and Sweden. Technological Forecasting \& Social Change.

Revest, V., Sapio, A. (2012). Financing Technology-based Small Firms in Europe: What do we Know? Small Business Economics 39, 179-205.

Rogers, J.D. (2013). Introducing the Special Section Theme: Recent Developments in Data Sources and Analysis for R\&D Evaluation. Research Evaluation 22, 269-271.

Romer, P.M. (1986). Increasing Returns and Long-Run Growth. Journal of Political Economy 94, 1002-1037.

Romer, P.M. (1990). Endogenous Technological Change. Journal of Political Economy 98,71102.

Schumpeter, J.A.(1912). Theorie der wirtschaftlichen Entwicklung, 2d ed., München und Leipzig: Duncker \& Humblot, 1926. Engl.ed. The theory of economic development, New York: Oxford University Press, 1934.

Schumpeter, J.A. (1942). Capitalism, Socialism, and Democracy. Harper Perennial, 1962.

Signori, A., Vismara, S. (2017). M\&A synergies and trends in IPOs. Technological Forecasting \& Social Change.

Solow, R. (1956). A Contribution to the Theory of Economic Growth. Quarterly Journal of Economics 70, 65-94.

Solow, R. (1957). Technical Change and the Aggregate Production Function. Review of Economics and Statistics 39, 312-320.

Storey, D.J., Tether, B.S. (1998). Public Policy Measures to Support New Technology-based Firms in the European Union. Research Policy 26, 1037-1057.

Teece, D.J. (1986). Profiting from Technological Innovation: Implications for Integration, Collaboration, Licensing, and Public Policy. Research Policy 15, 285-305.

Terrell, S.R. (2012). Mixed Methods Research Methodologies. The Qualitative Report 17, 254280.

Vilkkumaa, E., Salo, A., Liesiö, J., Siddiqui, A. (2015). Fostering breakthrough technologies — How do optimal funding decisions depend on evaluation accuracy? Technological Forecasting and Social Change, 96, 173-190. 
Zuniga-Vicente, A.J., Alonso-Borrego, C., Forcadell, F.J., Galàn, J.I. (2014). Assessing the effect of public subsidies on firm R\&D investment: a survey. Journal of Economic Surveys 28, 36-67.

Weber, K.M., Rohracher, H. (2012). Legitimizing research, technology and innovation policies for transformative change: Combining insights from innovation systems and multi-level perspective in a comprehensive failures framework. Research Policy, 41, 1037-1047.

Wooldridge, J. (2002). Econometric Analysis of Cross Section and Panel Data. MIT Press.

Wu, C.-H., Ding, C.G., Jane, T.-D., Lin, H.-R., Wu, C.-Y. (2015). Lessons from the global financial crisis for the semiconductor industry. Technological Forecasting and Social Change 99, 4753. 